\title{
Are services advertised differently? An empirical examination
}

\author{
Fean-Marc Décaudin \\ Université de Toulouse 1 Capitole (IAE), Toulouse Business School, Toulouse, France, and \\ Denis Lacoste \\ Toulouse Business School, Université de Toulouse, Toulouse, France
}

\begin{abstract}
Purpose - The objective of this paper is to study the relevance of a specific approach to services advertising by testing the absolute and relative impact of the product/service variable on advertising strategy.

Design/methodology/approach - A content study of 4,233 press advertisements, taken from generalist magazines, was conducted using an original analytical framework based on competitive advantage. This framework was used to measure the impact on the advertising strategy of the following variables: type of offer, type of market and industry.

Findings - The research indicates that three variables significantly influence advertising strategy: type of offer, type of market, and industry. However, the type of industry is the most influential variable. The study shows that the product/service contrast alone cannot adequately explain the choice of advertising strategy.

Research implications/limitations - The conclusions indicate that the product-service variable should not be used in isolation, but rather in combination with other variables such as the type of target and the nature of the sector. The research, however, does not enable one to determine the relevance of the advertising choices highlighted.

Practical implications - The framework can enable one to link marketing strategy to advertising strategy. It enables one to clearly pose the problem of advertising strategy upstream from questions of creative approach and executional tools.

Originality/value - This research shows that the product/service variable is not the best explanatory variable of the advertising strategy.
\end{abstract}

Keywords Services, Advertising, Competitive advantage

Paper type Research paper

An executive summary for managers and executive readers can be found at the end of this article.

\section{Introduction}

The specificities of services have engendered many studies concerning the particularities of their marketing and advertising compared to those of products (Edgett and Parkinson, 1993; Grove et al., 1995; Tripp, 1997; Mittal, 1999). This literature has led to precise managerial recommendations for the advertising of services. Nevertheless, the results of empirical studies are divergent, and do not confirm the specificities of the advertising of services. Starting from this observation, the objective of this research is to study the relevance of a specific approach to services advertising by testing the absolute and relative impact of the product/service variable on this advertising. To achieve this aim, an empirical study was conducted using an analytical framework based on the theory of competitive advantage. This study shows that if indeed the advertising of services differs from that of products, other variables influence it. In

The current issue and full text archive of this journal is available at www.emeraldinsight.com/0887-6045.htm

Journal of Services Marketing

24/7 (2010) 546-553

(C) Emerald Group Publishing Limited [ISSN 0887-6045]

[DOI 10.1108/08876041011081096] particular, it shows that the type of industry appears to be the determining element in advertising.

\section{Services advertising: what does the literature say?}

The authors specializing in the marketing of services agree on the following points that differentiate the advertising of services from that of products. First of all, for the same campaign, one must not forget that there are two targets: the consumer (Grönroos, 1990), strongly influenced in his perception of quality (expected service and perceived service) by advertising (Parasuraman et al., 1988), and employees (Abernethy and Butler, 1992). Indeed, many service firms are organized into networks (banks, insurance companies, car rental firms, etc.), which increases the need for communication between headquarters and employees in order to bridge the potential gap between external communication and the delivery of the service (Parasuraman et al., 1988).

Next, it is advisable to include in the advertising mix a technique such as word-of-mouth (George and Berry, 1981; Brown and Reingen, 1987; Hill and Gandhi, 1992), since personal experience plays an essential role (Grönroos, 1990). Also, building a strong service brand proves to be imperative

Received: July 2008

Revised: March 2009

Accepted: April 2009 
in reducing perceived risk, which is higher in services (Mortimer, 2002). Finally, the authors highlight the difficulty of advertising, due to the intangibility of services and the attendant difficulty for consumers to grasp the message (Zeithaml and Bittner, 2000). The consequences of this analysis regarding intangibility can be summarized in a succinct piece of managerial advice: the service on offer must be tangibilized in the advertising message (George and Berry, 1981; Legg and Baker, 1987; Hill and Gandhi, 1992; Mortimer, 2000) by providing tangible proof of the service and its interest, by making how it works understandable, and by showing the benefits it procures. This recommendation for the creation of an advertising message would enable, according to the authors, to create trust between the potential customer and the service brand, to facilitate the realization of the provision of the service and prepare repeat purchases, to create a specific style of advertising, and finally to lead and motivate collaborators, in particular the contact personnel.

Five main methods can be used in advertising to make the service more tangible and the communication more effective (Legg and Baker, 1987; Hill and Gandhi, 1992; Mortimer and Mathews, 1998). Two apply to the servuction itself (the contact personnel and the physical evidence), two to the outcome of the service delivery (guarantees and testimonial approaches; Mittal, 2002; Clow et al., 2006), and a last one applies to the elements used in the advertising:

- Using the service personnel has the advantage of concretizing the servuction situation while meeting the need to target this category of personnel. This advice is complemented by the recommendation to use company personnel instead of professional actors. IBM, for example, presents in its press campaigns its consulting engineers who work with customers. Internal casting sessions led to the selection of employees who best represent the corporate image from amongst the volunteers.

- Presenting physical evidence often enables the consumer to infer the quality of the service. Airline companies in their advertising campaigns show the layout of the cabin, which is a decisive element in the consumer's choice of long-haul flights.

- Proposing service guarantees such as a commitment to achieve defined results or showing past performance meets the objective of concretization.

- Choosing testimonial messages facilitates word-of-mouth and brings about a process of identification. This is what telephone and tour operators do.

- Using concrete signifiers for logos and appropriate slogans contributes to a materialization of the perception of the service on offer.

The literature highlights the characteristics that the advertising of services should have in order to overcome the difficulties linked to intangibility. This leads to the following research hypothesis:

H1. Advertising strategy depends on the type of offer (product or service)

It has to be pointed out, however, that despite many analyses, the differences between product and services advertising practices are still unclear (Mortimer, 2002). Moreover, it is mainly researchers in the marketing of services who have taken an interest in this question and not advertising specialists. This is all the more surprising given that knowledge of advertising has progressed greatly over the past 25 years. This focus (Mortimer, 2002) obscures the literature on advertising, in particular the work concerning the role of involvement in the advertising approach and more precisely Petty and Cacioppo's (1980) ELM model and its managerial application, the FCB grid (Vaughn, 1986; Ratchford, 1987). This grid enables a classification of markets according to the level of involvement (high or low) and the mode of influence (thinking or feeling). Several studies have highlighted the link between the characteristics of an offer based on these criteria and the nature of the advertising.

To complement the understanding of an advertising strategy adapted to services, Mortimer (2001) interviewed advertising professionals about their practices. What emerged from the interviews is that creative directors do not take into account the product/service distinction, even if they recognize the importance of the intangibility of services for advertising strategy. The specific objectives of each campaign are more decisive, as are the degree of involvement and the utilitarian or experiential nature of the offer.

These analyses regarding the non-use of the teachings of advertising research are complemented with criticisms aimed at the recommendations made by authors specializing in the marketing of services (Mittal, 1999) and presented as universal, independent of economic sector, culture, country, etc. In fact, the degree of intangibility of services varies greatly according to the type of industry. Intangibility is much less in retailing, for example, than in consulting. Already in 1983, Lovelock advocated the segmenting of services according to five criteria:

1 nature of the service act;

2 type of relationship with the customer;

3 level of customization and judgment in the service delivery;

4 nature of demand and supply; and

5 method of service delivery.

Furthermore, it has been shown that service advertising is not treated in the same way in all countries (Albers-Miller and Stafford, 1999), given that the use of the rational and emotional dimensions of advertising messages varies significantly from one country to another. Finally, it seems difficult to create an advertising strategy based only on these indications. This is the conclusion Carolyn Tripp (1997) reaches in her inventory and analysis of the literature on the subject.

All the criticisms aimed at the analyses and recommendations made by the authors specialized in the marketing of services lead one to reconsider the question of service advertising and to formulate other hypotheses that may complement, refine, or even invalidate $H 1$. Turley and Kelley (1997), for example, strongly encourage one to consider the nature of the target (business to business or business to consumer) as an essential criterion influencing the construction of the advertising message. Similarly, Grove et al. (1995), Mortimer (2000), as well as all the FCB grid applications (Ratchford, 1987; Rossiter et al., 1991) show that the type of industry directly influences the advertising message. In other words, services should not be considered a monolithic block, and it seems that certain types of service can be closer to certain product categories than to other services (Mortimer, 2000). 
These observations lead to the formulation of the following hypotheses:

H2. Advertising strategy depends on the type of target.

H3. Advertising strategy depends on the particular industry.

These hypotheses suggest that several different criteria can influence advertising strategy; it is therefore interesting to consider the relative importance of the criteria in terms of influencing such strategy, and to establish a hierarchy. The literature on advertising thus gives rise to the formulation of the following hypothesis:

H4. The particular industry has a greater influence on advertising strategy than the type of offer and type of target.

\section{The analytical model}

The analytical model must meet two objectives. First, it must enable one to characterize the advertising strategy and thus the main lines of expression of the specificity of the offer. Second, the model must have a dimension of universality; it must enable one to characterize both product advertisements and service advertisements (H1), both BtoB and BtoC advertisements (H2) and finally, any industrial sector (H3).

The extant analytical frameworks are based on specific elements such as advertising message appeals (rational versus emotional) and executional tools. These frameworks do not enable to meet the research objectives. On one hand, the criteria proposed are often very particular. For example, the criteria of Resnik and Stern (1977) have been criticized for their product orientation as regards categorization and measure (Mortimer, 2008). On the other hand, many frameworks aim to test the impact of only one advertising variable such as information content.

To develop an analytic model based on the expression of competitive advantage in the copy is therefore useful, since it meets the two defined objectives. Indeed, since competitive advantage has to be perceived by the target in order to create value, it is the central element in the communication strategy of the firm, whatever industrial sector it operates in. Four communication approaches are then possible: to present the competitive advantage itself, to highlight the means employed to create competitive advantage, to show the value created for the customer and finally, to emphasize the corporate commitments of the firm.

These elements give rise to the following model, as shown in Figure 1.

The analytical framework derived from this model can be seen in Table I. In order to verify the capacity of this framework to cover all advertising strategies, a pre-test was conducted on 300 magazine advertisements in order to assess the relevance of the model. The objective was to test whether, on one hand, all the variables of the model were necessary for

Figure 1 Advertising strategies

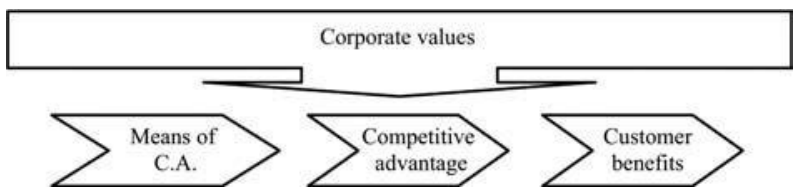

the analysis, and, on the other hand, whether these variables suffice to explain each of the messages studied.

The pre-test showed the relevance of the model, but also made it clear that a certain number of messages do not use any of the approaches listed above; instead, they simply present the offer without making any direct or indirect reference to competitive advantage. This variable was then added to the model. The definitive model thus has five variables. A second running of the pre-test enabled one to check whether all the advertisements could be classified according to one of the five variables, and whether each of the variables of the model was used a significant number of times. This result legitimates the use of the model in the framework of an analysis of advertisement content.

\section{Empirical research}

The methodology used is based on the analysis of the content of advertising messages. Content analysis is a frequently used method in advertising research (Kolbe and Burnett, 1991; Mortimer, 2008). Kassarjian (1977) is often cited as a reference for having highlighted the characteristics of an effective content analysis: objective (Berelson, 1971), systematic, quantitative and generalizable. The coding rules used in this research are directly derived from his recommendations.

The advertising messages were taken from four highcirculation, generalist French magazines over a one-year period. In total, 4,298 different advertisements were collected. Generalist magazines were chosen with a view to obtaining the widest possible coverage and representativeness of the different industry. All the advertisements in the selected magazines were analyzed, whatever their format. Any single advertisement was only analyzed once in order not to deform the results by taking into account the advertising pressure from a particular brand or industry (Spears et al., 2006). The advertising messages were coded separately by the authors. For each advertisement, the central advertising strategy was defined. When an advertisement has several messages, only the message perceived as the main one has been retained for consideration. In almost all cases, there was no ambiguity at all in identifying the central theme. If, after discussion, the coders still could not agree on a code, the advertisement was eliminated from the sample. A total of 65 advertisements were thus withdrawn from the initial base, so the final base was made up of 4,233 different advertisements.

To ensure the reliability of the coding, a sub-sample of 450 advertisements was submitted to two coders who were specialized in advertising but not aware of the hypotheses of the research. The first external coder is a marketing professor and the second is an advertising professional with more than 30 years experience in the domain. The two coders classified more than 90 percent of the advertisements in the same categories as the authors did (92 percent for the first and 95 percent for the second). This level of consistency can be considered satisfactory (Kassarjian, 1977). To test the hypotheses, it was identified for each advertisement, the type of offer (product or service), the type of target (business, consumer or both business and consumer) and the industry concerned.

Tables II and III present the advertising strategies chosen according to type of offer and target. Table IV shows the same information for each industry studied. 
Table I From advertising to executional tools

\begin{tabular}{|c|c|c|c|}
\hline Advertising strategy & Possible executional tools & $\begin{array}{l}\text { Examples of elements highlighted } \\
\text { for services }\end{array}$ & $\begin{array}{l}\text { Examples of elements highlighted } \\
\text { for products }\end{array}$ \\
\hline \multirow[t]{2}{*}{ Competitive advantage } & Price/differentiation & Yield on a financial investment & Fuel consumption \\
\hline & Personnel & Frontline personnel & $R \& D$ engineer \\
\hline Means of the competitive & Assets & Site of a resort hotel & Traditional know-how \\
\hline advantage & Competences & Experience of frontline personnel & Patents \\
\hline Customer benefits & Testimonial prescribers & Client in his hotel room & Cleaning product \\
\hline & & TO's commitment to develop eco- & \\
\hline Corporate values & Institutional commitments & tourism & Commitment to reducing pollution \\
\hline
\end{tabular}

Table II Advertising strategy by type of offer

\begin{tabular}{|c|c|c|c|}
\hline Advertising strategy & Sample (\%) & $\begin{array}{l}\text { Type of offer } \\
\text { Product ads (\%) }\end{array}$ & Service ads (\%) \\
\hline Presentation of the offer & 35.6 & 38.5 & 31.8 \\
\hline Means of competitive advantage & 6.9 & 1.8 & 13.7 \\
\hline Benefits & 23.1 & 21.4 & 25.4 \\
\hline Institutional commitment linked to values & 8.6 & 7 & 10.7 \\
\hline
\end{tabular}

Table III Advertising strategy by type of target

\begin{tabular}{|c|c|c|c|c|}
\hline \multirow[b]{2}{*}{ Advertising strategy } & \multicolumn{4}{|c|}{ Type of market } \\
\hline & Sample (\%) & $\mathrm{B}$ to $\mathrm{B}$ ads $(\%)$ & $\mathrm{B}$ to $\mathrm{C}$ ads $(\%)$ & Mixed-targets ads (B to B and B to C) (\%) \\
\hline Presentation of the offer & 35.6 & 24.5 & 39.1 & 13.8 \\
\hline Means of competitive advantage & 6.9 & 7.4 & 5.7 & 18.8 \\
\hline Benefits & 23.1 & 32.4 & 21.5 & 27.4 \\
\hline Institutional commitment linked to values & 8.6 & 12.2 & 7.6 & 14.8 \\
\hline
\end{tabular}

To test the first three hypotheses, chi square tests were performed. The results of these tests show that:

- The type of offer has a significant impact on the choice of advertising strategy. Service firms use different drivers in their advertising from those used by manufacturing companies making tangible goods (chi-square significant, $p<0.001) . H 1$ is supported.

- The type of market influences the choice of advertising strategy. Companies communicate differently to industrial customers compared to retail ones (chi-square significant $-p<0.001) . H 2$ is supported.

- Finally, the advertising strategy is influenced by the industry to which the company belongs. In orienting their creative strategy, advertisers thus take into account the particular nature of the product or service concerned (chisquare significant $-p<0.001)$. H3 is supported.

Beyond the validation of hypotheses, study of the data can lead to more qualitative analyses. First, the result of the research indicate that product advertisements and service advertisements differ mainly in that product advertisements make much more use of the presentation of the offer and competitive advantage, while service advertisements focus more on the means employed, customer benefits (this result is in line with previous studies) and institutional commitments. These observations are consistent with previous literature, which emphasizes the need to tangibilize the service through the advertising. Next, it is interesting to note that businessfocused advertising differs from consumer-focused advertising in that it makes greater use of benefits and institutional commitment, and to a lesser extent, means of communication. This is also in line with the analyses that point out the greater rationality of industrial purchases. Then, the research shows that each industry has a particular profile. One can observe for example that presentation of the offer is the main advertising strategy for industries as different as food and drink, publishing, personal equipment, cosmetics, retailing, tourism and entertainment. Competitive advantage is dominant for the automobile industry, intermediate goods, household furnishings, electronics and the hotel industry. Means of competitive advantage is never the primary strategy. 
Table IV Advertising strategy by industry

\begin{tabular}{|c|c|c|c|c|c|c|}
\hline \multirow[b]{2}{*}{ Code } & \multicolumn{6}{|c|}{ Advertising strategy } \\
\hline & Industry & $\begin{array}{l}\text { Presentation of } \\
\text { the offer } \\
(\%)\end{array}$ & $\begin{array}{c}\text { Competitive } \\
\text { advantage } \\
(\%)\end{array}$ & $\begin{array}{l}\text { Means used } \\
(\%)\end{array}$ & $\begin{array}{c}\text { Benefits } \\
(\%)\end{array}$ & $\begin{array}{l}\text { commitment } \\
\text { linked to values } \\
(\%)\end{array}$ \\
\hline \multicolumn{7}{|c|}{ Products } \\
\hline P1 & Food and drink & 30.3 & 26.6 & 0 & 18.6 & 24.5 \\
\hline P2 & Automobiles & 16.9 & 57.5 & 0 & 19.3 & 6.4 \\
\hline P3 & Intermediate goods & 0 & 42.6 & 10.6 & 0 & 46.8 \\
\hline P4 & Publishing & 81.3 & 7 & 6.3 & 3.9 & 1.6 \\
\hline P5 & Personal equipment & 67.1 & 8 & 2.2 & 19.1 & 3.6 \\
\hline P6 & Household furnishings & 22 & 57.1 & 4.4 & 12.1 & 4.4 \\
\hline P7 & Electronic equipment & 7.8 & 54.6 & 2.8 & 32 & 2.8 \\
\hline P8 & Cosmetics hygiene & 43.9 & 21.2 & 0 & 31 & 3.9 \\
\hline P9 & Pharmaceuticals & 0 & 0 & 0 & 58.8 & 41.2 \\
\hline \multicolumn{7}{|c|}{ Services } \\
\hline S1 & Banking and insurance & 10.2 & 27.9 & 6 & 43 & 12.8 \\
\hline S2 & Retailing & 39.9 & 20.2 & 7.8 & 19.2 & 13 \\
\hline S3 & Hotels and restaurants & 0 & 43.6 & 0 & 43.6 & 12.8 \\
\hline S4 & Other services & 44.9 & 13.2 & 5.9 & 21 & 15.1 \\
\hline S5 & Non-commercial services & 25.5 & 0 & 0 & 53.2 & 21.3 \\
\hline S6 & Télécommunications & 22.3 & 19.5 & 23.6 & 30.6 & 4 \\
\hline S7 & Tourism & 45.4 & 17.3 & 17.6 & 17 & 2.6 \\
\hline S8 & Transportation & 14.7 & 17.1 & 27.9 & 10.1 & 30.2 \\
\hline S9 & Entertainment & 81.5 & 0 & 18.5 & 0 & 0 \\
\hline
\end{tabular}

They constitute more than 15 percent of the advertisements in four industries:

1 telecommunications;

2 tourism;

3 transportation; and

4 entertainment.

Highlighting results is the primary advertising strategy for firms in the hotel sector, non-commercial services, telecommunications and pharmaceuticals. Finally, institutional commitment is dominant in two industries: intermediate goods and transportation.

The first three hypotheses having been verified, the question now at hand is that of the hierarchy between the determinants of choice of advertising strategy. A classification method appropriate for qualitative variables was used: the classification and regression tree (C\&RT). C\&RT is a nonparametric analysis technique. This technique allows partitioning a whole sample into subsets (or nodes) through successive binary splits. The child nodes are more homogeneous than their parent nodes in the response variable. C\&RT identifies the best explanatory variable and value at each step. Indices of node homogeneity (such as the Gini index, used in this research) guide the splitting process. In the research presented here, the dependent variable is the advertising strategy. The explanatory variables are the type of offer, the type of target and the industry. The result is presented in Figure 2.

Table $\mathrm{V}$ presents the profile of each group obtained in terms of advertising strategy.

The regression tree shows that the most discriminating variable is "industry": it is the only discriminating variable in the first two breakdowns. The variable "market" discriminates less since it only appears in the third stage of the breakdown. The variable "offer" discriminates very rarely since it does not appear until the third level of breakdown.

The industry itself, independently of its type (product or service), is the main explanatory variable of the advertising strategy chosen. Thus, for example, in the first breakdown, the first branch of the tree has four service industries and six product ones. The second branch is made up of five service industries and three product ones. This thus seems to confirm that advertisers are concerned primarily with the exact nature of the offer, independently of its degree of intangibility, in determining advertising strategy. These analyses lead one to consider that $\mathrm{H} 4$ supported.

\section{Discussion and conclusions}

The objective of this research was to re-examine the question of the relative influence of the type of offer (product or service) on advertising strategy. To do so, an analytical grid of corporate communication was constructed. Based on competitive advantage, it enabled to validate the impact of the type of offer on the advertising strategy chosen by the advertiser. Above all, it enabled to put this influence in perspective by showing that other variables can also explain the type of advertising (type of market and industry) and by demonstrating that the industry itself was the most discriminating variable. In other words, the study shows that the advertising approach depends first on the industry the company operates in and not on the product or service character of its offer. Services, just like products, are heterogeneous ensembles that it is useful to break down into sub-ensembles that present similarities and that can be approached in the same manner. This observation proves to 
Figure 2 Classification tree (breakdown into three levels)

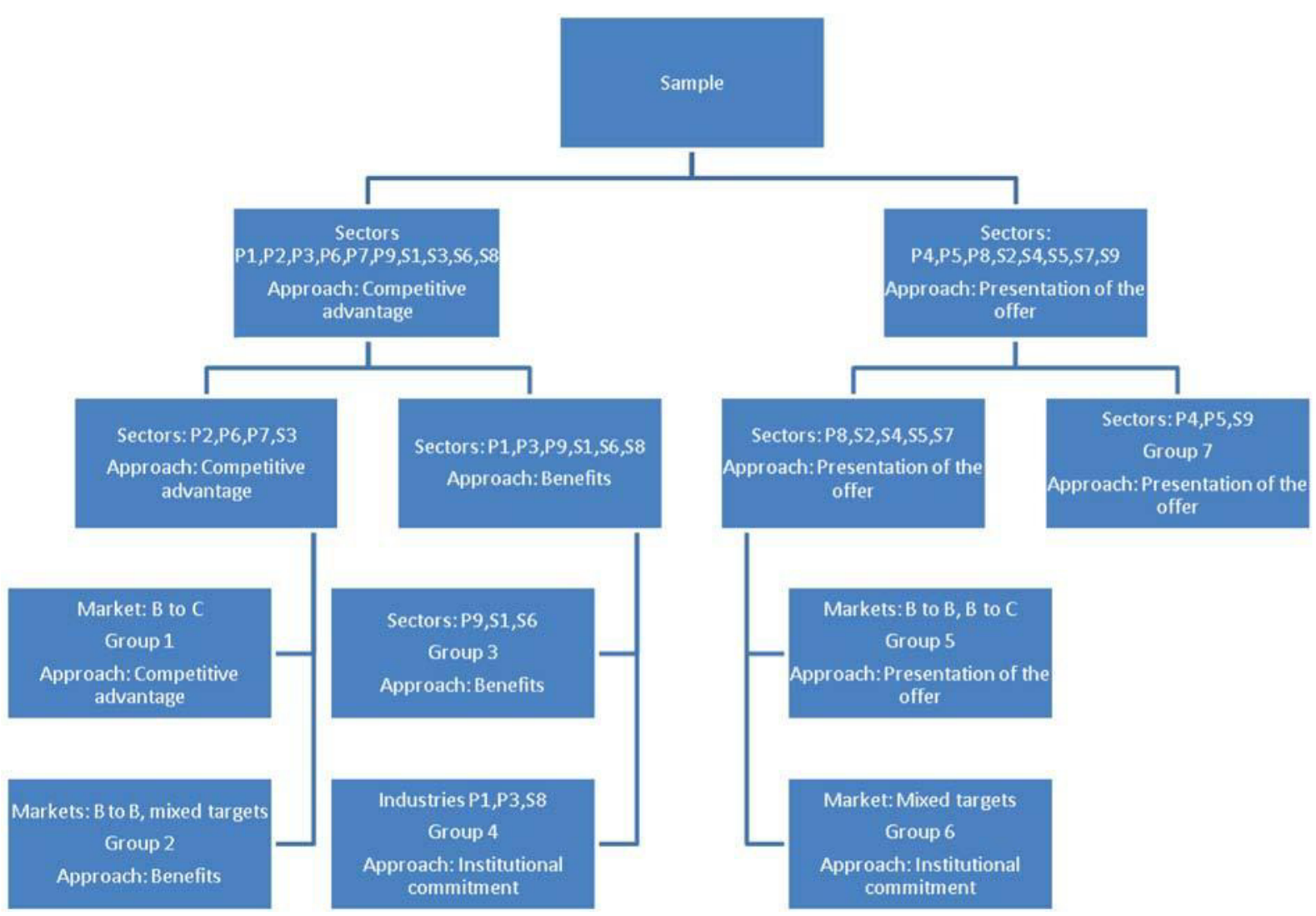

Table V Advertising strategy of the groups obtained by classification (percentage of ads using each advertising strategy)

\begin{tabular}{lccccccc}
\hline & Group 1 & Group 2 & Group 3 & Group 4 & Group 5 & Group 6 & Group 7 \\
\hline Presentation of the offer (\%) & 15 & 6.8 & 17 & 22 & 45 & 17.8 & 70 \\
Competitive advantage (\%) & 61 & 37.3 & 22 & 25 & 18.3 & 8.6 & 7.2 \\
Means of competitive advantage (\%) & 1 & 4.6 & 15.8 & 11 & 8 & 8.8 & 3.6 \\
Benefits (\%) & 18 & 45.4 & 36 & 13 & 22 & 17.8 & 16 \\
Institutional commitment linked to values (\%) & 5 & 5.9 & 9.2 & 29 & 6.7 & 47 & 3.2 \\
Size (no. ads) & 822 & 219 & 698 & 364 & 1,116 & 57 & 289 \\
\hline
\end{tabular}

be useful for the understanding of companies' advertising practices, practices that, as already mentioned, are not based on product/service characteristics (Mortimer, 2001).

The contributions of the study are thus both of a research and managerial nature. From a theoretical standpoint, the conclusions indicate that the product-service variable should not be used in isolation, but rather in combination with other variables such as the type of target and the nature of the sector. This conclusion is important, since studies that argue for the impact of the nature of the offer on advertising can make one lose sight of variables that are just as important, and indeed even more important. This research thus complements other studies that show that services are so heterogeneous that one cannot conceive of an advertising creation platform that would be suitable for all.

The methodology used can also contribute to further research. The analytic framework that has been constructed can be interesting for researchers who study companies' advertising strategies, as well as for those who wish to use a single framework to compare offers that differ widely in nature. The use of the C\&RT method has proven to be an effective one for measuring the respective impact of three influential variables on advertising strategy.

The proposed analytical framework can also be useful to managers. Indeed, it enables one to clearly pose the problem of advertising strategy, upstream from questions of creative approach and executional tools. Should one communicate on competitive advantage, on the bases of this advantage, on the customer benefits linked to this advantage, or on the commitments of the firm regarding this advantage? From this point of view, the framework can enable one to link marketing strategy to advertising strategy. It can help narrow the potential gap between service delivery and external communication (Parasuraman et al., 1988).

The results of the study can also be useful for decisionmakers. Indeed, the gap between authors' recommendations 
and corporate practice leads one to wonder whether practitioners sufficiently take into account the nature of the offer in the conception of their campaigns. Further research will thus be necessary to help them respond to this question and go beyond the limits of this study. As Mortimer (2008) mentions: "There is a dearth of research that examines service advertising effectiveness".

However, this study has a number of limitations. First of all, only the magazine press was used as media. It is possible that the nature of the media influences the advertising strategy used (Spears et al., 2006), and the replication of the study for other media would enable one to generalize (or not) the initial findings. Next, preliminary research has highlighted the importance of national context, while this study was limited to the French context. To reproduce the same study in other countries could show either the universality or the contingency of the conclusions. Finally, it would be interesting to use the impact scores of the advertising messages analyzed to be able to show the link between the choice of advertising strategy and its effectiveness.

\section{References}

Abernethy, A. and Butler, D. (1992), "Advertising information: services versus products", fournal of Retailing, Vol. 68 No. 4, pp. 398-419.

Albers-Miller, N.D. and Stafford, M.R. (1999), "An international analysis of emotional and rational appeals in services vs goods advertising", fournal of Consumer Marketing, Vol. 16 No. 1, pp. 42-57.

Berelson, B. (1971), Content Analysis in Communication Research, Hafner, New York, NY.

Brown, J. and Reingen, H. (1987), "Social ties and word-ofmouth referral behaviour", fournal of Consumer Research, Vol. 14 No. 3, pp. 350-62.

Clow, K.E., James, K.E., Kranenburg, K.E. and Berry, C.T. (2006), "The relationship of the visual element of an advertisement to service quality expectations and source credibility", fournal of Services Marketing, Vol. 20 No. 6, pp. 404-11.

Edgett, S. and Parkinson, S. (1993), "Marketing for service industries - a review", Service Industries fournal, Vol. 13 No. 3, pp. 19-39.

George, W.R. and Berry, L.L. (1981), "Guidelines for the advertising of services", Business Horizons, July-August, pp. 52-6.

Grönroos, Ch. (1990), Service Management and Marketing, Maxwell MacMillan International Editions, Basingstoke.

Grove, S., Pickett, G.M. and LaBand, D.N. (1995), "An empirical examination of factual information content of services advertisements", The Services Industries fournal, Vol. 15 No. 2, pp. 216-33.

Hill, D.J. and Gandhi, N. (1992), "Services advertising: a framework of its effectiveness", fournal of Services Marketing, Vol. 6 No. 4, pp. 63-76.

Kassarjian, H.H. (1977), "Content analysis in consumer research", Fournal of Consumer Research, Vol. 4, pp. 8-18.

Kolbe, R.H. and Burnett, M.S. (1991), "Content analysis research: an examination of applications with directives for improving research reliability and objectivity", fournal of Consumer Research, Vol. 18 No. 2, pp. 243-50.

Legg, D. and Baker, J. (1987), "Advertising strategies for service firms", in Surprenant, C. (Ed.), Add Value to Your Service, American Marketing Society, Chicago, IL, pp. 163-8.
Lovelock, Ch. (1983), "Classifying services to gain strategic marketing insights", fournal of Marketing, Vol. 47 No. 3, pp. 9-20.

Mittal, B. (1999), "The advertising of services: meeting the challenge of intangibility", fournal of Service Research, Vol. 2 No. 1, pp. 98-116.

Mittal, B. (2002), "Services communications: from mindless tangibilization to meaningful messages", fournal of Services Marketing, Vol. 16 No. 5, pp. 424-31.

Mortimer, K. (2000), "Are services advertised differently? An analysis of the relationship between product and service types and the informational content of their advertisements", fournal of Marketing Communication, Vol. 6 No. 2, pp. 121-34

Mortimer, K. (2001), "Services advertising: the agency viewpoint", fournal of Services Marketing, Vol. 15 No. 2, pp. 131-46.

Mortimer, K. (2002), "Integrating advertising theories with conceptual models of services advertising", fournal of Services Marketing, Vol. 16 No. 5, pp. 460-8.

Mortimer, K. (2008), "Indentifying the components of effective service advertisements", fournal of Services Marketing, Vol. 22 No. 2, pp. 104-13.

Mortimer, K. and Mathews, B. (1998), "The advertising of services: consumer views $\mathrm{v}$ normative guidelines", The Service Industries fournal, Vol. 18 No. 3, pp. 4-19.

Parasuraman, A., Zeithaml, V.A. and Berry, L.L. (1988), "Servqual: a multiple-item scale for measuring consumer perceptions of service quality", fournal of Retailing, Vol. 64 No. 1, pp. 12-37.

Petty, R.E. and Cacioppo, J.T. (1980), "Issue involvement as a moderator of the effects on attitude of advertising content and context", in Rent, B.M. (Ed.), Advances in Consumer Research, Volume VIII, Association for Consumer Research, Ann Arbor, pp. 20-4.

Ratchford, B.T. (1987), "New insights about the FCG grid", fournal of Advertising Research, August-September, pp. 24-38.

Resnik, A. and Stern, B.L. (1977), "An analysis of information content in television advertising", fournal of Marketing, Vol. 41 No. 1, pp. 50-3.

Rossiter, J., Percy, L. and Donovan, R.J. (1991), "A better advertising planning grid", fournal of Advertising Research, October-November, pp. 11-21.

Spears, N., Paswan, A.K. and Kahla, M. (2006), "Services dominated by maximal versus minimal-self contexts: verbal versus visual cues in services advertising", fournal of current issues and research in advertising, Vol. 28 No. 2, pp. 65-76.

Tripp, C. (1997), "Services advertising: an overview and summary of research, 1980-1995", fournal of Advertising, Vol. 26 No. 4, pp. 21-38.

Turley, L.W. and Kelley, S.W. (1997), "A comparison of advertising content: business to business versus consumer services", fournal of Advertising, Vol. 26 No. 4, p. 39.

Vaughn, R. (1986), "How advertising works: a planning model revisited", Fournal of Advertising Research, FebruaryMarch, pp. 57-66.

Zeithaml, V.A. and Bittner, M.J. (2000), Services Marketing: Integrating Customer Focus Across the Firm, McGraw-Hill, New York, NY.

\section{Further reading}

Abernethy, A. and Franke, G.R. (1996), "The information content of advertising: a meta-analysis", fournal of Advertising, Vol. XXV No. 2, pp. 1-17. 


\section{Corresponding author}

Denis Lacoste can be contacted at: d.lacoste@esc_toulouse.fr

\section{Executive summary and implications for managers and executives}

This summary has been provided to allow managers and executives a rapid appreciation of the content of this article. Those with a particular interest in the topic covered may then read the article in toto to take advantage of the more comprehensive description of the research undertaken and its results to get the full benefits of the material present.

Despite many analyses, the differences between product and services advertising practices are still unclear. Surprisingly, given the great increase in knowledge about advertising during the past 25 years or so, it is still mainly researchers in the marketing of services who have taken an interest in this question and not advertising specialists.

The aim of Jean-Marc Décaudin and Denis Lacoste in "Are services advertised differently? An empirical examination" is to study the relevance of a specific approach to services advertising by testing the absolute and relative impact of the product/service variable on this advertising. They conclude that if indeed the advertising of services differs from that of products, other variables influence it. In particular, it shows that the type of industry appears to be the determining element in advertising. The study supports their assertions that:

- advertising strategy depends on the type of offer (product or service);

- advertising strategy depends on the type of target;

- advertising strategy depends on the particular industry; and

- the particular industry has a greater influence on advertising strategy than the type of offer and type of target.

There is agreement on several points which differentiate the advertising of services from that of products: first, there are two targets: the consumer, strongly influenced in his perception of quality (expected service and perceived service) by advertising, and employees. Indeed, many service firms are organized into networks (banks, insurance companies, car rental firms, etc.), which increases the need for communication between headquarters and employees in order to bridge the potential gap between external communication and the delivery of the service.

Next, it is advisable to include in the advertising mix a technique such as word-of-mouth, since personal experience plays an essential role. Also, building a strong service brand proves to be imperative in reducing perceived risk, which is higher in services. Finally, the difficulty of advertising, due to the intangibility of services and the attendant difficulty for consumers to grasp the message. The consequences of this analysis regarding intangibility can be summarized in a succinct piece of managerial advice: the service on offer must be tangibilized in the advertising message by providing tangible proof of the service and its interest, by making how it works understandable, and by showing the benefits it procures.

This recommendation for the creation of an advertising message could create trust between the potential customer and the service brand, facilitate the realization of the provision of the service and prepare repeat purchases, create a specific style of advertising, and finally to lead and motivate collaborators, in particular the contact personnel.

Five main methods can be used in advertising to make the service more tangible and the communication more effective:

1 Using the service personnel has the advantage of concretizing the servuction situation while meeting the need to target this category of personnel. This advice is complemented by the recommendation to use company personnel instead of professional actors. IBM, for example, presents in its press campaigns its consulting engineers who work with customers. Internal casting sessions led to the selection of employees who best represent the corporate image from amongst the volunteers.

2 Presenting physical evidence often enables the consumer to infer the quality of the service. Airline companies in their advertising campaigns show the layout of the cabin, which is a decisive element in the consumer's choice of long-haul flights.

3 Proposing service guarantees such as a commitment to achieve defined results or showing past performance meets the objective of concretization.

4 Choosing testimonial messages facilitates word-of-mouth and brings about a process of identification. This is what telephone and tour operators do.

5 Using concrete signifiers for logos and appropriate slogans contributes to a materialization of the perception of the service on offer.

The degree of intangibility of services, however, varies greatly according to the type of industry. For example, it is much less in retailing than in consulting. The advertising approach depends first on the industry the company operates in and not on the product or service character of its offer. Services, just like products, are heterogeneous ensembles that it is useful to break down into sub-ensembles.

The product-service variable should not be used in isolation, but rather in combination with other variables such as the type of target and the nature of the sector. This is important, since studies that argue for the impact of the nature of the offer on advertising can make one lose sight of variables that are just as important, and indeed even more important. Services are so heterogeneous that one cannot conceive of an advertising creation platform that would be suitable for all.

The authors' analytic framework enables one to clearly pose the problem of advertising strategy, upstream from questions of creative approach and executional tools.

(A précis of the article "Are services advertised differently? An empirical examination". Supplied by Marketing Consultants for Emerald.) 